\title{
High Temperature Selenidization of Metallic Zirconium
}

\author{
Kenji YAMADA, Futoshi HORIKAWA and Yoshinori SASAKI* \\ Received February 8, 1993 ; Accepted April 5, 1993
}

\section{INTRODUCTION}

The metal selenides become important as functional inorganic materials. For example, molybdenum selenides are used as solid lubricants. Particularly noteworthy is the zinc monoselenide as a blue LED (Light Emitting Diode).

As part of a series of studies on the formation reactions of metal selenides, the selenidization of zirconium at high temperatures was investigated.

\section{EXPERIMENTAL}

A zirconium sheet $1 \mathrm{~mm}$ thick with a purity of 99.8 wt\%, supplied by The Nilaco corporation, was cut into rectangular pieces of approximately $6 \mathrm{~mm} \times 25 \mathrm{~mm}$. These pieces were vacuum annealed at $850^{\circ} \mathrm{C}$ for $4 \mathrm{~h}$ and polished with emery papers then with finely divided chromium (III) oxide on a wet polishing cloth. A sample sheet and an excess of selenium shots with a purity of $99.999 \mathrm{wt} \%$ were placed at each end of a one-side closed silica tube. This tube was sealed under vacuum. The selenidizations of zirconium were carried out at temperatures of 500 to $650^{\circ} \mathrm{C}$. During the selenidization, the lowest temperature zone was kept at $433^{\circ} \mathrm{C}$, so the vapor pressure of selenium was held at 10 Torr $\left.(1.33 \mathrm{kPa})^{1}\right)$. The apparatus and experimental procedures employ. ed in this study have been described in detail in a previous paper 2 ).

Department of Applied Chemistry, Faculty of Engineering, Chiba University (Yayoi-cho, Inage-ku, Chiba 263 Japan) Key Words: Selenidization, Zirconium Selenide $\left(\mathrm{ZrSe}_{2}\right)$, Parabolic Rate Constant

\section{EXPERIMENTAL RESULTS}

\subsection{Kinetic rates}

Plots of the mass gain per unit area against a square root of the reaction time are shown in Fig. 1. Each datum point represents the selenidization of individual specimens. At all the reaction temperatures the plots yield straight lines, showing that these selenidizations obeyed a parabolic rate law; hence the rate-determining step is apparently a diffusion process in the selenide layers. The parabolic rate constants obtained from the slopes of these straight lines are listed in Table 1. An only report ${ }^{3}$ ) of the rates of selenidization of zirconium has been presented at $534^{\circ} \mathrm{C}$ under selenium vapor pressures of $0.026-17.59 \mathrm{kPa}$, using a silica-spring thermogravimetric apparatus, in which the selenidizations were revealed to obey a parabolic rate law at comparatively lower pressures but not to do at higher pressures. Their apparatus and reaction conditions differ widely from those in the present study.

\subsection{Compositions of zirconium selenide films}

The $\mathrm{x}$ - ray diffraction peaks of powders of the selenide films obtained under all the reaction conditions employed, using nickel-filtered copper radiation, belonged mainly to $\mathrm{ZrSe}_{2}$ (hexagonal)4 6).

Table 1 Parabolic rate constants $K_{p}$ for selenidization of zirconium under the selenium vapor pressure of $10 \mathrm{Torr}$.

\begin{tabular}{cc}
\hline Temperature/C & $\mathrm{K}_{\mathrm{p}} / \mathrm{mg}^{2} \mathrm{~cm}^{-4} \mathrm{~h}^{-1}$ \\
\hline 500 & $0.41 \pm 0.04$ \\
550 & $1.18 \pm 0.08$ \\
600 & $3.56 \pm 0.22$ \\
650 & $11.0 \pm 0.7$ \\
\hline
\end{tabular}




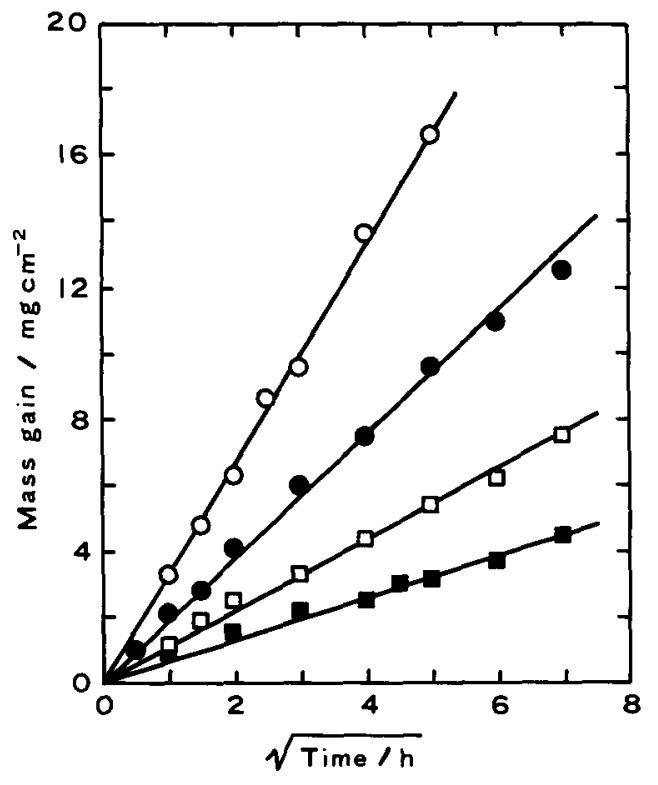

Fig. 1 Parabolic plots of selenidization of zirconium under the selenium vapor pressure of 10 Torr: $650^{\circ} \mathrm{C} ; 600^{\circ} \mathrm{C} ; \square 550^{\circ} \mathrm{C}, \square 00^{\circ} \mathrm{C}$.

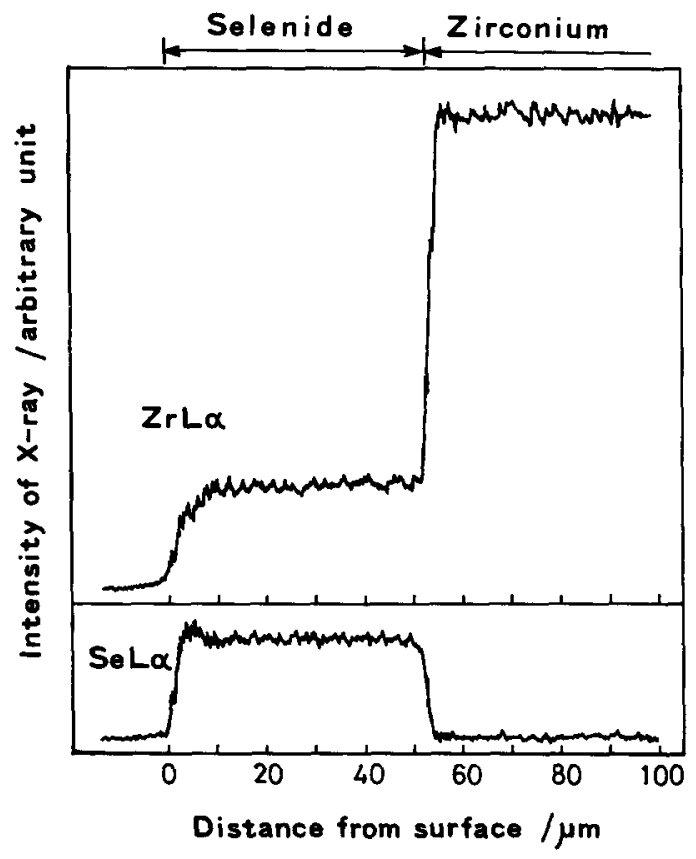

Fig. 2 Distribution profiles of selenium and zirconium in the selenide films $\left(650^{\circ} \mathrm{C}-10\right.$ Torr $\left.-25 \mathrm{~h}\right)$.
Composition variations through the selenide films were examined by an electron probe microanalyzer. The specimen selenidized at $650^{\circ} \mathrm{C}$ was embeded in an acrylic resin, and then the cross section was polished with $0.5 \mu \mathrm{m}$ diameter diamond paste. The results of line analysis across the cross section of this film for each element are illustrated in Fig. 2. It is clear that the intensities of $\mathrm{ZrL} \alpha$ and SeLa are nearly constant through the selenide film. The somewhat higher intensity of SeLa in the neighborhood of the surface is assumed to represent a dissolution of Se in the $\mathrm{ZrSe}_{2}$ matrix and/or a penetration of Se into the crystal grain boundaries of $\mathrm{ZrSe}_{2}$. It was also confirmed that the molar ratio of $\mathrm{Se} / \mathrm{Zr}$, obtained from the selenium weight gained and the weight loss of metal zirconium with respect to the selenide film shown in Fig. 2, was 2.06.

From these facts, the selenide films were concluded to have been mainly composed of $\mathrm{ZrSe}_{2}$.

\section{CONCLUSIONS}

Zirconium sheet samples were selenidized at $500-650^{\circ} \mathrm{C}$ under the selenium vapor pressure of 10 Torr by a sealed-tube method. These selenidizations proceeded according to a parabolic rate law under all the reaction conditions employed. $\mathrm{X}$-ray diffraction patterns and an electron probe microanalysis of product films indicated the selenide films to have been mainly composed of $\mathrm{ZrSe}_{2}$.

\section{REFERENCES}

1) Kagakubenran Kiso-hen II [Handbook of Pure Chemistry] (ed., Chemical Society of Japan), Maruzen Co., Tokyo, p. II-115 (1984).

2) K. Takahashi and Y. Sasaki, Bull. Chem. Soc. Jpn., 65, 329 (1992).

3) J.E. Dutrizac, Can, Met. Quart., 24, 375 (1985).

4) JCPDS Powder Diffraction File, card 3-1189.

5) A. Gleizes and Y. Jeannin, J. Solid State Chem., 1, 180 (1970).

6) L. Brattås and A. Kjekshus, Acta Chem. Scand., 27, 1290 (1973). 